\title{
Managing Dynamic Competition
}

\author{
By TRacy R. Lewis AND Huseyin YILDIRIM*
}

\begin{abstract}
In many important high-technology markets, including software development, data processing, communications, aeronautics, and defense, suppliers learn through experience how to provide better service at lower cost. This paper examines how a buyer designs dynamic competition among rival suppliers to exploit learning economies while minimizing the costs of becoming locked in to one producer. Strategies for controlling dynamic competition include the handicapping of more efficient suppliers in procurement competitions, the protection and allocation of intellectual property, and the sharing of information among rival suppliers. (JEL C73, D44, L10)
\end{abstract}

In many industries learning by doing or learning through production experience enables suppliers to reduce costs. ${ }^{1}$ This is particularly important in high-tech markets including computer hardware and software, microprocessors, electronics, aeronautics, and defense. This paper examines how a buyer optimally manages dynamic competition among rival suppliers to exploit learning economies.

To motivate and illustrate our analysis, let us briefly describe some market competition experiments we have conducted with University of Florida MBA students. The experiment in-

\footnotetext{
* Lewis: Department of Economics, University of Florida, Gainesville, FL 32611 (e-mail: lewistr@dale.cba.ufl. edu); Yildirim: Department of Economics, Duke University, Durham, NC 27708 (e-mail: yildirh@econ.duke.edu). We thank an anonymous referee and seminar participants at Columbia University, Duke University, North Carolina State University, the University of Florida, the University of Pennsylvania, the University of Texas (Austin), and the University of Wisconsin (Madison) for their valuable comments. We also thank Jeff Baxter for his help on simulations.

${ }^{1}$ These industries include, for instance, nuclear power (Paul L. Joskow and George A. Rozanski, 1979; Peter C. Roberts and Calvin C. Burwell, 1981; Richard K. Lester and Mark J. McCabe, 1993), chemicals (Robert B. Stobaugh and Patrick L. Townsend, 1975; Marvin B. Lieberman, 1984), airplanes (T. P. Wright, 1936; Armen Alchian, 1963), ships (Leonard Rapping, 1965; Peter Thompson, 2001; Rebecca A. Thornton and Thompson, 2001), machine tools (Werner Z. Hirsch, 1952, 1956), computers and semiconductors (William W. Nye, 1996; Harald Gruber, 1998), and electrical equipment (Lee E. Preston and E. C. Keachie, 1964; Ralph G. M. Sultan, 1975).
}

volves three groups of students who repeatedly compete with each other to supply one unit of a commodity to a single buyer. The commodity yields a surplus of $V=300$ to the buyer. Each period, seller $i$ 's supply cost, $C\left(x_{i}, c_{i}\right)=$ $c\left(x_{i}\right)+c_{i}$, is the sum of two costs. $c\left(x_{i}\right)$, is a known production cost which declines with $x_{i}$, the number of times seller $i$ has previously supplied the buyer. Reductions in production cost reflect savings a seller achieves from learning by doing. For the experiment reported here the sequence of production costs are $\{200,190$, $160,145,135,125,110,105,100\}$, respectively, for $x_{i}=0,1,2, \ldots, 8$. Learning economies are exhausted after eight supply experiences so that $c\left(x_{i}\right)=100$ for $x_{i} \geq 8$. The second cost, $c_{i}$, is a random operating cost. $c_{i}$ is independently and identically distributed over time and across sellers. $c_{i}$ assumes values of $\{10,20,30,40,50\}$ with equal probability.

The experiment proceeds as follows: Beginning each period the sellers learn their supply costs. A seller's production cost, $c\left(x_{i}\right)$ is known by the buyer and other sellers since the sales history is public knowledge. However, a seller's random operating cost for the period, $c_{i}$, is private knowledge. Next, each seller submits a sealed-bid price to the buyer. The buyer then selects one seller to supply the good at the price offered. The transaction is completed, whereupon the process begins again in the next period. The sellers' objective is to maximize the sum of profits over time. The buyer's objective 
TABle 1-Summary of EXPERIMENTAL Results

\begin{tabular}{lcccccccccc}
\hline \hline & \multicolumn{10}{c}{ Period } \\
\cline { 2 - 10 } & 1 & 2 & 3 & 4 & 5 & 6 & 7 & 8 & 9 & 10 \\
\hline Buyer's surplus & 100 & 110 & 125 & 145 & 125 & 115 & 120 & 130 & 130 & 130 \\
Winning seller & B & C $^{\mathrm{a}}$ & A & A & B & C & A & A & A & A \\
Seller surplus & -10 & -20 & -50 & -40 & -40 & -5 & -30 & 5 & 0 & 10 \\
\hline
\end{tabular}

${ }^{\text {a }} \mathrm{C}$ was not the lowest-priced seller.

is to minimize the total costs of procuring the commodity. ${ }^{2}$

We have conducted this experiment eight times with different groups of subjects. The results recorded in Table 1 for one of the experiments are typical of what we observed. The table displays the net surplus the buyer received (300 minus the supply price), the identity of the winning seller, A, B, or C, and his profit (supply price minus supply cost) for each period.

The outcome depicted in Table 1 indicates the following:

Penetration Pricing by Sellers.-Sellers competed vigorously in early periods, offering prices which were less than their supply costs. Only in the later periods do sellers begin to earn positive profits. Our subjects indicated they initially discounted prices to penetrate the market, and reduce costs in subsequent periods through production experience.

Buyer Surplus Was Brought Forward.-The seller's penetration pricing provided the buyer with significant surplus early on, even before sellers had moved down their learning curves.

Buyer Encourages Rivalry.- - In periods 2 and 6 of the experiment, the buyer purchased from seller $\mathrm{C}$, even though a rival seller offered a lower price. The buyer indicated to us that he selected the higher-priced seller, $\mathrm{C}$, to enable

\footnotetext{
${ }^{2}$ The group of sellers achieving the highest profit was awarded a $\$ 50$. prize. Several sets of experiments were conducted. The buyer who achieved the greatest net surplus among all the experiments that were conducted was also awarded a $\$ 50$. prize. The experiments ran for approximately two hours. The students only knew that the competition would last for some indeterminant number of periods.
}

him to move down its learning curve and maintain cost parity with the other suppliers.

Market Tipping.-During the initial periods, sellers $\mathrm{A}, \mathrm{B}$, and $\mathrm{C}$ took turns at winning the competition. As indicated above, the buyer facilitated this process by occasionally selecting a higher-period seller. This was done to maintain parity between the suppliers. Eventually, however, supplier A gained a sufficient cost advantage to become the dominant supplier. In effect the market tipped entirely to A.

This paper analyzes how to design optimal procurements when suppliers learn from production experience. The aforementioned experiments provide some ideas and insights for us to build upon. Perhaps the best-known examples of repeated procurements where learning by doing occurs are the Department of Defense (DoD) purchases of weapon systems, aircraft, and missiles; see John R. Fox (1988) and Jacques S. Gansler (1989). Several strategic, structural, and policy issues influence the design of optimal procurements in this setting. First, among strategic issues there is the experiencecompetition trade-off to resolve. Awarding the current procurement to the more experienced, lower-cost producer minimizes current acquisition costs. However, subsequent procurements become less competitive if one supplier gets too far ahead of his rivals. Second, there is the rivalry effect to consider. Do competing suppliers bid more aggressively when they are close or distant rivals in terms of their relative production costs? And, how does the procurer account for this rivalry in selecting a supplier each period? Third, how is the optimal procurement strategy affected by the tenure and preferences of the procurer, and by the supply-side market structure? Finally, there are policy questions. 
Are competitive procurements efficient? Does learning occur at the socially desired rate?

A review of our central findings suggests the optimal behavior of buyers and sellers in multiperiod procurements with learning is consistent with the behavior demonstrated in our experiments. In particular, we find:

(i) When learning economies are significant, the buyer optimally evolves to contracting with a single supplier and market tipping occurs. Although the buyer eventually becomes locked in to one producer, he benefits from the initial competition among suppliers for market dominance and from the potential competition of remaining suppliers. When learning is less pronounced the buyer permanently rotates his purchases among different suppliers to maintain competition in the market.

(ii) The procurer does not necessarily benefit as suppliers learn from experience. The buyer may incur greater acquisition costs as the higher-cost supplier becomes more experienced. Although the experience reduces that supplier's cost, it may lessen competition between the suppliers. The overall effect may be to drive up the buyer's future acquisition cost.

(iii) Learning may occur too slowly under competitive procurement. To maintain competitive parity among suppliers, the procurer may prevent one supplier from moving too far ahead on his experience curve. To expedite learning the buyer may require suppliers to share information acquired from production experience. The procurer may disseminate information acquired by one supplier to another when he owns or controls the production process.

(iv) Another remedy for slow learning is the rotating of program managers among different acquisition. This is a practice the DoD frequently follows. Short-term managers minimize the short-run cost of acquisition without regard for the effect of their behavior on future procurement costs. Consequently the shortlived manager procures from the more efficient firm thus increasing the rate of learning.
The remainder of the paper begins with the presentation of our model in Section I. For concreteness, we model the process of a recurring defense acquisition. The procurer auctions off a supply contract each period to two competing suppliers who are privately informed of their production costs. Each supplier's cost is decreasing in his production experience. We model the interaction between the suppliers and the procurer as a dynamic game, and demonstrate a unique Markov-Perfect Equilibrium (MPE) to this game exists.

Section II describes the properties of the MPE. We describe how the suppliers compete and how the procurer favors or handicaps the more efficient supplier in current-period auctions. We examine the social value and private value of production experience to the procurer in Section III. We demonstrate that the social and private value of experience may be negative in some settings. In Section IV, we analyze how different procurement policies the DoD has adopted affect the rate of learning. These policies include the mandatory sharing of information among suppliers, the merging of suppliers, and limiting the purchaser's tenure. We conclude the paper in Section V with a summary of findings and suggestions for future research. We shall relate our analysis to the relevant literature on procurement in the course of our discussion.

The proofs of Lemma 1 and Proposition 1 are contained in the Appendix. The proofs of our remaining results, Proposition 2-10, are similar to the proof of Proposition 1 and therefore omitted. Complete proofs are available from the authors.

\section{Procurement Model}

In this section we first describe the procurement model, and then characterize the equilibrium procurement behavior. Readers who are more interested in the policy implications of our analysis may wish to skim this section and proceed to our discussion of procurement policy beginning in Section II.

\section{A. Description of the Model}

Our procurement model is similar to the experiment setting we described above. Each 
period a procurer purchases exactly one unit of a good or service from one of the two suppliers. ${ }^{3}$ The buyer values the good at $V>0$. This value is sufficiently large that the buyer always decides to procure the good. ${ }^{4}$ For supplier $i=$ 1,2 , the cost, $C\left(x_{i}, c_{i}\right)$, of supplying the good is

$$
C\left(x_{i}, c_{i}\right)=c\left(x_{i}\right)+c_{i}
$$

In equation (1), $c\left(x_{i}\right)$ is an intrinsic cost of production which depends on $x_{i}=0,1,2, \ldots$, the number of times producer $i$ has previously supplied the procurer. Intrinsic costs are decreasing in $x_{i}$ as the supplier learns to reduce costs from the experience of previous production. Producers learn only from their own experience; there is no diffusion of information across producers, at least for now. Eventually each supplier reaches the bottom of his learning curve. Opportunities for further learning are exhausted after he has supplied $h$ units. Formally we require: ${ }^{5}$

\section{ASSUMPTION 1:}

$$
c\left(x_{i}\right) \begin{cases}>c\left(x_{i}+1\right) & \text { for } \quad x_{i}<h \\ =c(h) & \text { for } \quad x_{i} \geq h\end{cases}
$$

The second cost component in equation (1), $c_{i}$, is a transitory cost. It is known privately by supplier $i$, and it depends on producer $i$ 's current operating conditions and access to inputs. The costs, $c_{i}$ for $i=1,2$ are independently and identically distributed each period and across suppliers by density $f\left(c_{i}\right){ }^{6}$ For simplicity, we assume $f\left(c_{i}\right)$ is the uniform distribution with $c_{i} \in[0, \bar{c}]$ and $\bar{c}>0$ throughout. Finally, we assume there are no fixed costs to production.

\footnotetext{
${ }^{3}$ Duplicative purchases are not optimal provided the costs of production is sufficiently large relative to the learning economies arising from production.

${ }^{4}$ Assuming the good is always purchased simplifies our model, but it is not essential for the analysis to follow.

${ }^{5}$ It is possible to allow costs to remain the same for several states or decrease with experience without changing our main results. The assumption that costs reach a minimum after finite experience allows us to employ backwardinduction arguments to prove many of our results.

${ }^{6}$ In what follows, we assume $i, j=1,2$ and $i \neq j$.
}

The interaction between the procurer and two suppliers is governed by a sequence of auctions organized as follows:

(i) Each period, before meeting, each seller privately observes its transitory cost, $c_{i}$.

(ii) The procurer offers a trading mechanism for that period in which both suppliers confidentially report their private transitory costs to the buyer. The procurer promises to pay suppliers an amount $P_{i}(\mathbf{x}, \mathbf{c})$, conditioned on the state $\mathbf{x}=\left(x_{1}, x_{2}\right)$, and on their cost reports, $\mathbf{c}=\left(c_{1}, c_{2}\right)$. Further, the procurer requires producer $i$ to provide the good with probability $\lambda_{i}(\mathbf{x}, \mathbf{c}) \in[0,1]$ with $\lambda_{1}(\mathbf{x}, \mathbf{c})+\lambda_{2}(\mathbf{x}, \mathbf{c})=1$. $^{7}$

(iii) Each supplier accepts or rejects the procurer's offer. (In equilibrium all suppliers agree to the offer.)

(iv) Finally, suppliers simultaneously and confidentially report their costs, $c_{i}$, to the procurer. The procurer picks one of the suppliers to produce the good, and pays the producers according to the contract. After production, the experience state, $\mathbf{x}$, is updated, whereupon the next procurement competition commences.

There are several noteworthy features of our model. First, we are addressing multiperiod procurements with learning. ${ }^{8}$ Earlier analyses by Jean J. Laffont and Jean Tirole (1987), Preston R. McAfee and John McMillan (1987), and Michael H. Riordan and David E. M. Sappington (1987) characterize optimal procurement auctions but for one-time purchases only. Lewis (1983), James J. Anton and Dennis A. Yao (1987), Joel S. Demski et al. (1987), James D. Dana and Kathryn E. Spier (1994), and Philippe Jehiel et al. $(1996,1999)$ deal with sequential procurements and analyze how potential future competition among suppliers affects their current behavior. These analyses do not assume firms learn from previous production, which is

\footnotetext{
${ }^{7}$ Recall, we assume the procurer always purchases the good from one of the suppliers.

${ }^{8}$ It is important to analyze repeated procurements which last for an indefinite number of periods to account for the variety of strategies and behaviors that suppliers and buyers may adopt in learning situations.
} 
essential to our investigation. Luis M. B. Cabral and Riordan (1994) analyze settings where buyers change each period so that they are unconcerned how their current acquisition affects future competition. Our analysis complements and extends Cabral and Riordan (1994) to analyze market competition when consumers as well as suppliers act strategically.

Second, since each seller's costs, $c_{i}$, are serially uncorrelated, private information is temporary in our setting. Consequently suppliers do not reveal information about their future costs from their current actions. We abstract from strategic learning to focus on the effects of learning by doing. ${ }^{9}$

Third, due to well-known political and legal constraints we posit that the procurer can not commit to a long-term acquisitions policy. Instead, the procurer offers a sequence of onetime supply competitions which she revises after each period. ${ }^{10,11}$

Finally we model the dynamic relation between the procurer and two suppliers as an infinitehorizon Markov game. We examine MPE, where players' strategies depend on their private information (for sellers) and the current state, $\mathbf{x}$. Our restriction to Markov behavior also has intuitive appeal as we wish to highlight the effects of learning by doing on parties' behaviors.

\section{B. Characterization of Equilibrium}

Let $B(\mathbf{x}), S_{1}(\mathbf{x})$, and $S_{2}(\mathbf{x})$ represent the expected discounted present value for the buyer

\footnotetext{
${ }^{9}$ The effects of strategic learning on optimal procurement practices are surveyed in Laffont and Tirole (1993). Some interesting analysis of strategic learning in other multiperiod settings include Aldo Rustichini and Asher Wolinsky (1995), Dirk Bergemann and Juuso Valimaki (1996), Roberto Burguet (1996), and Godfrey Keller and Sven Rady (1999).

${ }^{10}$ Laffont and Tirole (1988) present an analysis of repeated procurements in which the procurer is able to commit to a long-term acquisition policy. Our analysis precludes long-term commitments.

${ }^{11}$ Government procurements are limited in duration. Administrative rules prohibit long-term commitments and appropriations. This originates from the belief that a currently elected official should not be able to bind future elected officials to a course of action. Regarding private procurements, incompleteness of contracts and enforcement problems make it unlikely that a buyer and seller can commit themselves to long-term supply policy.
}

and for seller 1 and 2, respectively, of participating in the procurement given the current state, $\mathbf{x}$. All parties attach a weight of $\delta \in(0,1)$ to future payments and costs. ${ }^{12}$

Recall each period the buyer offers a procurement menu $\left\{P_{i}(\mathbf{x}, \mathbf{c}), \lambda_{i}(\mathbf{x}, \mathbf{c})\right\}$ for seller $i$ to select from. Given this menu, we define seller $i$ 's value function $S_{i}(\mathbf{x})$ by the following

$$
\begin{aligned}
S_{i}(\mathbf{x}) & \equiv E_{c} S_{i}(\mathbf{x}, \mathbf{c}) \\
& \equiv E_{c_{i}} S_{i}\left(\mathbf{x}, c_{i}\right)
\end{aligned}
$$

where $E$ is the expectation operator and

$$
\text { (3) } \begin{aligned}
S_{i}\left(\mathbf{x}, c_{i}\right)= & \max _{\tilde{c}_{i}} E_{c_{j}}\left\{P_{i}\left(\mathbf{x}, \tilde{c}_{i}, c_{j}\right)\right. \\
& +\lambda_{i}\left(\mathbf{x}, \tilde{c}_{i}, c_{j}\right)\left[-c\left(x_{i}\right)\right. \\
& \left.-c_{i}+\delta S_{i}\left(x_{i}+1, x_{j}\right)\right] \\
& \left.+\lambda_{j}\left(\mathbf{x}, \tilde{c}_{i}, c_{j}\right) \delta S_{i}\left(x_{i}, x_{j}+1\right)\right\} .
\end{aligned}
$$

In (3), $S_{i}\left(\mathbf{x}, c_{i}\right)$ denotes seller $i$ 's expected surplus given state, $\mathbf{x}$, and his private cost, $c_{i}$. Seller $i$ selects a cost report $\tilde{c}_{i}$ to maximize his expected payment $P_{i}(\cdot)$ plus his expected surplus when he wins the procurement and when supplier $j$ wins. With probability $\lambda_{i}(\cdot)$, seller $i$ produces and incurs costs $c\left(x_{i}\right)+c_{i}$. He also gains production experience enabling him to earn an expected continuation value of $\delta S_{i}\left(x_{i}+\right.$ $\left.1, x_{j}\right)$. When seller $j$ wins, which occurs with probability $\lambda_{j}(\cdot)$, seller $i$ inherits a continuation value of $\delta S_{i}\left(x_{i}, x_{j}+1\right)$.

To implement an allocation the buyer offers a menu $\left\{P_{i}(\mathbf{x}, \mathbf{c}), \lambda_{i}(\mathbf{x}, \mathbf{c})\right\}$ satisfying incentive compatibility (IC) and individual rationality (IR). An incentive compatible allocation induces the suppliers to truthfully report their private costs to the procurer. Employing usual methods, ${ }^{13}$ one can show from (3) that IC requires that for all $\mathbf{c}$ :

\footnotetext{
${ }^{12}$ In our proof of existence and uniqueness of MPE in Proposition 1, we demonstrate these functions exist and they are well defined.

${ }^{13}$ For instance, see Chapter 7 of Drew Fudenberg and Tirole (1991)
} 
(IC) $\lambda_{i}\left(\mathbf{x}, c_{i}\right) \equiv E_{c_{j}} \lambda_{i}(\mathbf{x}, \mathbf{c})$

is weakly decreasing in $c_{i}$, and

$$
d S_{i}\left(\mathbf{x}, c_{i}\right) / d c_{i}=-\lambda_{i}\left(\mathbf{x}, c_{i}\right) .
$$

Satisfying IR requires for all $c_{i}$,

$$
S_{i}\left(\mathbf{x}, c_{i}\right) \geq \delta S_{i}\left(x_{i}, x_{j}+1\right) .
$$

IR indicates that if seller $i$ decides not to participate in the current procurement, the buyer will select the rival seller $j$ to supply. This means that $i$ will inherit the experience state $\left(x_{i}, x_{j}+1\right)$ and corresponding continuation value of $\delta S_{i}\left(x_{i}, x_{j}+1\right)$ next period. In effect, $\delta S_{i}\left(x_{i}, x_{j}+1\right)$ determines seller $i$ 's reservation level of surplus in the current period. ${ }^{14}$

Combining IC and IR, we characterize implementible procurements given in the following lemma which employs this notation:

$$
\begin{aligned}
& \Delta_{x_{i}} S_{i}(\mathbf{x}) \equiv S_{i}\left(x_{i}+1, x_{j}\right)-S_{i}\left(x_{i}, x_{j}\right) \\
& \Delta_{x_{j}} B(\mathbf{x}) \equiv B\left(x_{i}, x_{j}+1\right)-B\left(x_{i}, x_{j}\right) .
\end{aligned}
$$

LEMMA 1: For any procurement allocation satisfying IC and IR, $\lambda_{i}\left(\mathbf{x}, c_{i}\right)$ is weakly decreasing in $c_{i}$, and

$$
\begin{aligned}
P_{i}\left(\mathbf{x}, c_{i}\right)= & \int_{c_{i}}^{\bar{c}} \lambda_{i}\left(\mathbf{x}, c_{i}^{\prime}\right) d c_{i}^{\prime}+\lambda_{i}\left(\mathbf{x}, c_{i}\right)\left[c\left(x_{i}\right)\right. \\
& \left.+c_{i}-\delta \Delta_{x_{i}} S_{i}(\mathbf{x})+\delta \Delta_{x_{j}} S_{i}(\mathbf{x})\right] .
\end{aligned}
$$

\section{PROOF:}

See the Appendix.

The buyer offers a procurement menu $\left\{P_{i}(\mathbf{x}, \mathbf{c})\right.$, $\left.\lambda_{i}(\mathbf{x}, \mathbf{c})\right\}$ to seller $i$ satisfying IC and IR to

\footnotetext{
${ }^{14}$ To insure participation by each seller, the buyer makes the following offer: Suppose seller 1 refuses to participate. The buyer then offers a price of $P$ to seller 2 to supply the object in the current period. $P$ is sufficiently large to insure participation by seller 2 . Therefore seller 1 will agree to participate provided his expected utility exceeds $\delta S_{1}\left(x_{1}\right.$, $\left.x_{2}+1\right)$ which is the surplus he earns if he refuses to participate.
}

maximize her expected surplus $B(\mathbf{x})$, defined recursively by

$$
\begin{aligned}
B(\mathbf{x})= & E_{c}\left\{V-P_{1}(\mathbf{x}, \mathbf{c})-P_{2}(\mathbf{x}, \mathbf{c})\right. \\
& +\delta\left[B(\mathbf{x})+\lambda_{1}(\mathbf{x}, \mathbf{c}) \Delta_{x_{1}} B(\mathbf{x})\right. \\
& \left.\left.+\lambda_{2}(\mathbf{x}, \mathbf{c}) \Delta_{x_{2}} B(\mathbf{x})\right]\right\} .
\end{aligned}
$$

According to (4), $B(\mathbf{x})$ consists of the net expected value of current consumption $V$, minus payments to the sellers, $P_{1}(\mathbf{x}, \mathbf{c})+P_{2}(\mathbf{x}, \mathbf{c})$. In addition, the buyer receives her continuation surplus, $\delta B(\mathbf{x})$, plus the future expected increase in surplus from production experience, $\delta\left[\lambda_{1}(\mathbf{x}, \mathbf{c}) \Delta_{x_{1}} B(\mathbf{x})+\lambda_{2}(\mathbf{x}, \mathbf{c}) \Delta_{x_{2}} B(\mathbf{x})\right]$.

Substituting the expressions for payments, $P_{i}(\cdot)$, from Lemma 1 into (4) enables us to concisely represent the buyer's value function as:

$$
\begin{aligned}
B(\mathbf{x})= & E_{\mathbf{c}} \max _{\left\{\lambda_{1}\left(\mathbf{x}, c_{1}\right), \lambda_{2}\left(\mathbf{x}, c_{2}\right)\right\}}\left\{\left[\lambda_{1}(\mathbf{x}, \mathbf{c}) z_{1}\left(\mathbf{x}, c_{1}\right)\right.\right. \\
& \left.+\lambda_{2}(\mathbf{x}, \mathbf{c}) z_{2}\left(\mathbf{x}, c_{2}\right)\right]+\delta B(\mathbf{x}) \\
& \left.-\delta\left[\Delta_{x_{2}} S_{1}(\mathbf{x})+\Delta_{x_{1}} S_{2}(\mathbf{x})\right]\right\}
\end{aligned}
$$

where

$$
\begin{aligned}
z_{i}\left(\mathbf{x}, c_{i}\right) \equiv & V-c\left(x_{i}\right)-c_{i} \\
& -F\left(c_{i}\right) / f\left(c_{i}\right)+\delta \Delta_{x_{i}} W(\mathbf{x}) \\
W(\mathbf{x}) \equiv & B(\mathbf{x})+S_{1}(\mathbf{x})+S_{2}(\mathbf{x}) .
\end{aligned}
$$

According to (5), the buyer selects the seller generating the largest surplus, $z_{i}$. This surplus equals the value of consumption minus production costs, $V-c\left(x_{i}\right)-c_{i}$, minus information rents, $F\left(c_{i}\right) / f\left(c_{i}\right)$ accruing to seller $i$, plus the increase in the future total surplus, $\delta \Delta_{x_{i}} W(\mathbf{x})$ occurring as supplier $i$ gains experience from current production. ${ }^{15}$

\footnotetext{
${ }^{15}$ For a sufficiently low $V$, it is possible that $z_{i}\left(x, c_{i}\right) \leq 0$, in which case the buyer will optimally set $\lambda_{i}(\cdot)=0$. If this holds for both suppliers, then the buyer may delay purchasing the good for one period. However, allowing for this possibility does not change our qualitative results. Thus, to avoid unnecessary complications we assume $V$ is sufficiently large that the buyer always purchases from one supplier each period.
} 
A MPE for our procurement game consists of a set of best-reply strategies for the buyer and two sellers conditioned on the state $\mathbf{x}$ (and on $\mathbf{c}$ for sellers) in each period. The buyer's strategy, $\left\{\lambda_{1}(\mathbf{x}, \mathbf{c}), \lambda_{2}(\mathbf{x}, \mathbf{c})\right\}$, maximizes her payoff as defined in (5). In deriving (5), we have already required the truthful reporting of information and the participation strategies to be Bayesian best responses to each other. Further, these strategies are best responses to the buyer's contract offers for all conceivable histories of the game, summarized by the evolution of the state, $\mathbf{x}$. Consequently the strategy $\left\{\lambda_{1}(\mathbf{x}, \mathbf{c}), \lambda_{2}(\mathbf{x}, \mathbf{c})\right\}$ maximizing the buyer's payoff in (5) as well as the sellers' reporting and participation strategies constitute a MPE. The unique MPE for the procurement game described above is characterized by:

PROPOSITION 1: There exists a unique and seller-symmetric MPE to the procurement game satisfying (3), (IC), (IR), and (5) with these properties:

$$
\lambda_{1}\left(k, l, c^{\prime}, c^{\prime \prime}\right)=\lambda_{2}\left(l, k, c^{\prime \prime}, c^{\prime}\right)
$$

$$
\begin{aligned}
S_{i}(\mathbf{x})= & E_{c}\left\{\lambda_{i}(\mathbf{x}, \mathbf{c}) \frac{F\left(c_{i}\right)}{f\left(c_{i}\right)}\right\} \\
& +\delta S_{i}\left(x_{i}, x_{j}+1\right)
\end{aligned}
$$

(c) $B(\mathbf{x})$

$$
=\frac{E_{c}\left\{\max _{i \in\{1,2\}} z_{i}\left(\mathbf{x}, c_{i}\right)\right\}-\delta\left[\Delta_{x_{2}} S_{1}(\mathbf{x})+\Delta_{x_{1}} S_{2}(\mathbf{x})\right]}{1-\delta} .
$$

The equilibrium is symmetric with regards to the producers as reflected in (a). According to (b) each seller receives his reservation surplus $\delta S_{i}\left(x_{i}, x_{j}+1\right)$ plus his expected information rents, $E_{c}\left\{\lambda_{i}(\mathbf{x}, \mathbf{c})\left[F\left(c_{i}\right) / f\left(c_{i}\right)\right]\right\}$. The buyer limits seller $i$ 's future surplus to this value, by setting payments to tax away all excess surplus. Condition (c) indicates the buyer's surplus is the discounted sum of the maximum of the surplus $z_{i}\left(\mathbf{x}, c_{i}\right)$ she receives from supplier $i$ minus $\delta\left[\Delta_{x_{2}} S_{1}(\mathbf{x})+\Delta_{x_{1}} S_{2}(\mathbf{x})\right]$ which is additional surplus the buyer captures by threatening to exclude either seller from the current procurement competition.

\section{Procurement Competition}

How are procurements determined by the suppliers' experience? Is the more experienced and efficient producer favored by the buyer to win the next competition? Does this probability of winning increase as the leading producer gains experience? Or, does the buyer favor lagging firms in future procurements to restore market parity as some policy analysts advocate? And finally how are suppliers' expected future profits affected by their winning or losing a current procurement? This determines how suppliers compete to enhance their future prospects.

To address these questions we begin by identifying the buyer's criterion for selecting a supplier. In what follows we designate supplier 1 as the leading producer with $x_{1} \geq x_{2}$. Recall the buyer selects the producer yielding the greatest increase in net surplus, $z_{i}\left(\mathbf{x}, c_{i}\right)=V-c\left(x_{i}\right)-$ $c_{i}-F\left(c_{i}\right) / f\left(c_{i}\right)+\delta \Delta_{x_{i}} W(\mathbf{x})$ each period. The buyer will select supplier 1 provided $z_{1}(\mathbf{x}$, $\left.c_{1}\right) \geq z_{2}\left(\mathbf{x}, c_{2}\right)$. Recalling $F\left(c_{i}\right)=c_{i} / \bar{c}$ and simplifying terms, the criterion for selecting producer 1 reduces to:

$$
c_{1} \leq c_{2}+\frac{a(\mathbf{x})}{2}
$$

where

$$
\begin{aligned}
a(\mathbf{x}) \equiv & c\left(x_{2}\right)-c\left(x_{1}\right) \\
& +\delta\left[\Delta_{x_{1}} W(\mathbf{x})-\Delta_{x_{2}} W(\mathbf{x})\right] .
\end{aligned}
$$

The buyer selects producer 1 if transitory cost, $c_{1}$, is sufficiently low as indicated by (6). The likelihood the procurer selects supplier 1 increases with $a(\mathbf{x})$ which is supplier 1's advantage over supplier 2. According to (7), this advantage consists of a cost differential and an experience differential. The cost differential, $c\left(x_{2}\right)-c\left(x_{1}\right)$, measures 1's intrinsic cost advantage in supplying the current good. The experience differential, $\delta\left[\Delta_{x_{1}} W(\mathbf{x})-\right.$ $\left.\Delta_{x_{2}} W(\mathbf{x})\right]$, measures the discounted increase in future total surplus if supplier 1 rather than supplier 
2 is selected. It depends on the suppliers' learning rates, and how they compete as rivals becoming closer or more distant.

To illustrate the separate effects of the cost and experience differentials on procurement, we start by analyzing the special no-discounting case where $\delta \rightarrow 1$. In what follows we denote $\bar{\lambda}_{i}(\mathbf{x}) \equiv E_{c} \lambda_{i}(\mathbf{x}, \mathbf{c})$ as the expected probability that supplier $i$ is assigned production in state $\mathbf{x}$.

PROPOSITION 2: As $\delta \rightarrow 1, a(\mathbf{x})=0$, and $\bar{\lambda}_{1}(\mathbf{x})=\bar{\lambda}_{2}(\mathbf{x})=1 / 2$ for all $\mathbf{x}$.

The finding in Proposition 2 is striking and ironic. Since the future is so important one would expect the procurer to expedite learning by favoring the supplier with more experience. Rather, Proposition 2 and equation (7) imply experience does not matter in making current procurement decisions. The supplier with the lowest transitory cost, $c_{i}$, produces each period, regardless of whether he is currently the lowest total-cost supplier.

The explanation for this finding is when future costs are undiscounted the buyer minimizes the average cost of procurement over all time. Eventually, this requires each supplier to operate at the bottom of his learning curve. A strategy of selecting the supplier with the lowest transitory cost clearly minimizes the sum of transitory costs incurred. Further, the sum of intrinsic costs incurred is the same for any strategy requiring both suppliers to eventually reach the minimum of their learning curves. To see this, note the total sum of intrinsic costs incurred for both sellers to reach the bottom of their intrinsic cost curve, $2 \sum_{i=0}^{h-1} c(i)$, is independent of the sequence in which the producers arrive at their cost minimums. Therefore selecting the lowest transitory cost supplier is the cost-minimizing strategy. ${ }^{16}$

Proposition 2 also states that the buyer does not impute any advantage to the lower-cost supplier in the current procurement as $a(\mathbf{x})=0$. When the future is very important the experi-

\footnotetext{
16 This result is a reminiscent of Michael A. Spence (1981), and Cabral and Riordan (1994), who also find that when there is no discounting, firms would compete as if they reached the bottom of their learning curves. However, buyers do not act strategically in their models.
}

ence differential in (7), $\delta\left[\Delta_{x_{1}} W(\mathbf{x})-\Delta_{x_{2}} W(\mathbf{x})\right]$ is negative and it exactly offsets firm 1's cost advantage, $c\left(x_{2}\right)-c\left(x_{1}\right)$. This occurs because the buyer desires to maintain parity between the suppliers to enhance future competition. In effect, the buyer favors the lessefficient supplier in the current procurement by ignoring the fact its intrinsic costs are higher.

More generally, when agents discount the future, we find the strategy for selecting contractors is modified. The procurer may still favor the less-experienced contractor, but not so much as to ignore his cost advantage. Now the procurer is more likely to select the leading producer each period. Further, the leader's competitive advantage may grow as he gains experience relative to his rival. The market may even tip to one supplier, by which we mean the procurer excludes the lagging producer from future competition if he falls too far behind. These findings are summarized in the following two propositions:

PROPOSITION 3: Suppose $\delta \in(0,1)$. Then,

$$
\bar{\lambda}_{1}(\mathbf{x}) \geq \bar{\lambda}_{2}(\mathbf{x})
$$

(with $>$ when $h \geq x_{1}>x_{2}$ ). For $\delta$ sufficiently small, or $h=2$,

(b) $\Delta_{x_{1}} \bar{\lambda}_{1}(\mathbf{x}) \geq 0$

$$
\Delta_{x_{1}} S_{1}(\mathbf{x}) \geq 0 \quad \Delta_{x_{1}} S_{2}(\mathbf{x}) \leq 0
$$

(c) $\Delta_{x_{2}} \bar{\lambda}_{1}(\mathbf{x}) \leq 0$

$$
\Delta_{x_{2}} S_{1}(\mathbf{x}) \leq 0 \quad \Delta_{x_{2}} S_{2}(\mathbf{x}) \geq 0
$$

(with strict inequalities if $\lambda_{1}(\mathbf{x})<1$ ).

PROPOSITION 4: Suppose costs decline uniformly with experience so that $c\left(x_{i}\right)-c\left(x_{i}+\right.$ $1)=\theta>0$ for all $x_{i} \leq h-1$. Then for a fixed distribution of transient costs, $c_{i}$, tipping occurs when $\theta$ is sufficiently large. Tipping does not occur whenever $\theta$ is small.

Part (a) of Proposition 3 indicates the leader's cost advantage is decisive in giving him a positive advantage, $a(\mathbf{x})>0$ in winning the next 
Table 2-Selection Probabilities and Supplier Values

\begin{tabular}{|c|c|c|c|c|c|}
\hline \multirow[b]{3}{*}{ Costs } & \multirow{2}{*}{$\frac{c_{1}(0)=8}{\bar{\lambda}_{1}(\mathbf{x})}$} & \multirow{2}{*}{$\frac{c_{1}(1)=7.5}{\bar{\lambda}_{1}(\mathbf{x})}$} & \multirow{2}{*}{$\frac{c_{1}(2)=7}{\bar{\lambda}_{1}(\mathbf{x})}$} & \multirow{2}{*}{$\frac{c_{1}(3)=6.5}{\bar{\lambda}_{1}(\mathbf{x})}$} & \multirow{3}{*}{$\begin{array}{c}c_{1}(4)=6 \\
\bar{\lambda}_{1}(\mathbf{x}) \\
S_{1}(\mathbf{x}) \quad S_{2}(\mathbf{x})\end{array}$} \\
\hline & & & & & \\
\hline & $S_{1}(\mathbf{x}) \quad S_{2}(\mathbf{x})$ & $S_{1}(\mathbf{x}) \quad S_{2}(\mathbf{x})$ & $S_{1}(\mathbf{x}) \quad S_{2}(\mathbf{x})$ & $S_{1}(\mathbf{x}) \quad S_{2}(\mathbf{x})$ & \\
\hline$c_{2}(4)=6$ & $\begin{array}{c}0.000 \\
0.000 \quad 2.247\end{array}$ & $\begin{array}{c}0.186 \\
0.378 \quad 1.941\end{array}$ & $\begin{array}{c}0.357 \\
1.005 \quad 1.765\end{array}$ & $\begin{array}{c}0.453 \\
1.437 \quad 1.691\end{array}$ & $\begin{array}{c}0.500 \\
1.667 \quad 1.667\end{array}$ \\
\hline$c_{2}(3)=6.5$ & $\begin{array}{c}0.000 \\
0.0002 .046\end{array}$ & $\begin{array}{c}0.210 \\
0.385 \quad 1.717\end{array}$ & $\begin{array}{c}0.396 \\
1.022 \quad 1.535\end{array}$ & $\begin{array}{c}0.500 \\
1.460 \quad 1.460\end{array}$ & $\begin{array}{c}0.547 \\
1.691 \quad 1.437\end{array}$ \\
\hline$c_{2}(2)=7$ & $\begin{array}{c}0.000 \\
0.000 \quad 1.642\end{array}$ & $\begin{array}{c}0.278 \\
0.416 \quad 1.269\end{array}$ & $\begin{array}{c}0.500 \\
1.087 \quad 1.087\end{array}$ & $\begin{array}{c}0.604 \\
1.535 \quad 1.022\end{array}$ & $\begin{array}{c}0.643 \\
1.765 \quad 1.005\end{array}$ \\
\hline$c_{2}(1)=7.5$ & $\begin{array}{c}0.004 \\
0.000 \quad 0.983\end{array}$ & $\begin{array}{c}0.500 \\
0.541 \quad 0.541\end{array}$ & $\begin{array}{c}0.722 \\
1.269 \quad 0.416\end{array}$ & $\begin{array}{c}0.790 \\
1.717 \quad 0.385\end{array}$ & $\begin{array}{c}0.814 \\
1.941 \quad 0.378\end{array}$ \\
\hline$c_{2}(0)=8$ & $\begin{array}{cc} & 0.500 \\
0.167 & 0.167\end{array}$ & $\begin{array}{c}0.996 \\
0.9830 .000\end{array}$ & $\begin{array}{c}1.000 \\
1.642 \quad 0.000\end{array}$ & $\begin{array}{c}1.000 \\
2.0460 .000\end{array}$ & $\begin{array}{c}1.000 \\
2.2470 .000\end{array}$ \\
\hline
\end{tabular}

Notes: Parameter values for this example are $\bar{c}=1, \delta=0.9$, and $V=10 . c_{1}\left(x_{1}\right)$ and $c_{2}\left(x_{2}\right)$ show intrinsic costs for supplier 1 and 2 , respectively.

procurement. When agents discount the future, the leader's current cost advantage more than compensates for the effects of diminished competition among suppliers that may occur in the future. Cabral and Riordan (1994) find a similar market dominance result in their analysis of learning and market competition. The findings in (b) and (c) that each supplier's surplus is increasing in his own experience and decreasing in the experience of his rival is intuitive and we conjecture these results hold generally. ${ }^{17}$

Proposition 4 indicates the procurer will alternate using different suppliers provided learning economies are sufficiently small relative to the possible variation in transient costs, i.e., when $\theta$ is small relative to $\bar{c}$. When there is large variation in supply costs between different producers each period, the buyer benefits from diversifying her purchases and maintaining the option of having two or more suppliers to select from in the future. It is only when learning economies are so large that one producer be-

\footnotetext{
${ }^{17}$ Laffont and Tirole $(1988,1993)$ also consider repeated auctions in which learning by doing occurs. In their model, the procurer optimally commits to favor or handicap the incumbent supplier in future auctions in order to induce the right amount of current-period production and learning. Our findings are not directly comparable to Laffont and Tirole $(1988,1993)$ as long-term commitments are ruled out in our analysis.
}

comes the low-cost supplier in all instances that tipping arises. ${ }^{18}$

The observations of Propositions 3 and 4 are illustrated in Table 2 which records the equilibrium supplier payoffs and supplier selection decisions for a typical procurement setting. In the example there are effectively 25 experience states $^{19}\left(x_{1}, x_{2}\right)$ where $x_{i}=0,1,2,3,4$ and learning is exhausted after four supply experiences. Starting in state $(0,0)$ at the bottom left side of the table, movements along a row represent an increase in seller 1's experience, and movements up a column correspond to an increase in seller 2's experience. The intrinsic costs for the supplier in states $x_{i}=0,1,2,3$, 4 are respectively $(8,7.5,7,6.5,6)$ as indicated in Table 2. The variable operating cost for each supplier is uniformly distributed each period over the $[0,1]$ interval. The buyer's surplus is 10 and the discount factor $\delta=0.90$. The payoffs $S_{1}$ and $S_{2}$ for suppliers 1 and 2, and supplier 1's expected probability of winning the

\footnotetext{
${ }^{18}$ Our analysis assumes inactive suppliers have no fixed costs and that they do not exit from the market. This means that the leading supplier still faces potential competition from his rival when the market has tipped entirely in his favor. This would arise if sellers who are inactive in the procurement market remain in business by serving buyers in other markets as well.

${ }^{19}$ Note states $\left(x_{1}, x_{2}\right)$ where $x_{i} \geq 4$ for $i=1,2$ are payoff-equilvalent to the state $\left(x_{1}=4, x_{2}=4\right)$.
} 
Table 3-Current-Period Expected Payments and Profits

\begin{tabular}{|c|c|c|c|c|c|c|c|c|c|c|}
\hline \multirow[b]{2}{*}{ Cost } & \multicolumn{2}{|c|}{$c_{1}(0)=8$} & \multicolumn{2}{|c|}{$c_{1}(1)=7.5$} & \multicolumn{2}{|c|}{$c_{1}(2)=7$} & \multicolumn{2}{|c|}{$c_{1}(3)=6.5$} & \multicolumn{2}{|c|}{$c_{1}(4)=6$} \\
\hline & $\begin{array}{r}P_{1}(\mathbf{x}) \\
\pi_{1}(\mathbf{x}) \\
\end{array}$ & $\begin{array}{l}P_{2}(\mathbf{x}) \\
\pi_{2}(\mathbf{x})\end{array}$ & $\begin{array}{r}P_{1}(\mathbf{x}) \\
\pi_{1}(\mathbf{x}) \\
\end{array}$ & $\begin{array}{l}P_{2}(\mathbf{x}) \\
\pi_{2}(\mathbf{x})\end{array}$ & $\begin{array}{r}P_{1}(\mathbf{x}) \\
\pi_{1}(\mathbf{x}) \\
\end{array}$ & $\begin{array}{l}P_{2}(\mathbf{x}) \\
\pi_{2}(\mathbf{x})\end{array}$ & $\begin{array}{r}P_{1}(\mathbf{x}) \\
\pi_{1}(\mathbf{x})\end{array}$ & $\begin{array}{l}P_{2}(\mathbf{x}) \\
\pi_{2}(\mathbf{x})\end{array}$ & $\begin{array}{r}P_{1}(\mathbf{x}) \\
\pi_{1}(\mathbf{x})\end{array}$ & $\begin{array}{l}P_{2}(\mathbf{x}) \\
\pi_{2}(\mathbf{x})\end{array}$ \\
\hline$c_{2}(4)=6$ & $\begin{array}{l}0.000 \\
0.000\end{array}$ & $\begin{array}{l}6.725 \\
0.225\end{array}$ & $\begin{array}{r}1.365 \\
-0.067\end{array}$ & $\begin{array}{l}5.460 \\
0.223\end{array}$ & $\begin{array}{r}2.561 \\
-0.038\end{array}$ & $\begin{array}{l}4.302 \\
0.200\end{array}$ & $\begin{array}{l}3.138 \\
0.050\end{array}$ & $\begin{array}{l}3.652 \\
0.179\end{array}$ & $\begin{array}{l}3.333 \\
0.167\end{array}$ & $\begin{array}{l}3.333 \\
0.167\end{array}$ \\
\hline$c_{2}(3)=6.5$ & $\begin{array}{l}0.000 \\
0.000\end{array}$ & $\begin{array}{l}7024 \\
0.024\end{array}$ & $\begin{array}{r}1.542 \\
-0.076\end{array}$ & $\begin{array}{l}5.519 \\
0.047\end{array}$ & $\begin{array}{r}2.846 \\
-0.045\end{array}$ & $\begin{array}{l}4.202 \\
0.055\end{array}$ & $\begin{array}{l}3.469 \\
0.052\end{array}$ & $\begin{array}{l}3.469 \\
0.052\end{array}$ & $\begin{array}{l}3.652 \\
0.179\end{array}$ & $\begin{array}{l}3.138 \\
0.050\end{array}$ \\
\hline$c_{2}(2)=7$ & $\begin{array}{l}0.000 \\
0.000\end{array}$ & $\begin{array}{r}7.301 \\
-0.199\end{array}$ & $\begin{array}{r}2.049 \\
-0.106\end{array}$ & $\begin{array}{r}5.226 \\
-0.119\end{array}$ & $\begin{array}{r}3.603 \\
-0.064\end{array}$ & $\begin{array}{r}3.603 \\
-0.064\end{array}$ & $\begin{array}{l}4.202 \\
0.055\end{array}$ & $\begin{array}{r}2.846 \\
-0.045\end{array}$ & $\begin{array}{l}4.302 \\
0.200\end{array}$ & $\begin{array}{r}2.561 \\
-0.038\end{array}$ \\
\hline$c_{2}(1)=7.5$ & $\begin{array}{r}0.031 \\
-0.002\end{array}$ & $\begin{array}{r}7.475 \\
-0.491\end{array}$ & $\begin{array}{r}3.699 \\
-0.217\end{array}$ & $\begin{array}{r}3.699 \\
-0.217\end{array}$ & $\begin{array}{r}5.226 \\
-0.119\end{array}$ & $\begin{array}{r}2.049 \\
-0.106\end{array}$ & $\begin{array}{l}5.519 \\
0.047\end{array}$ & $\begin{array}{r}1.542 \\
-0.076\end{array}$ & $\begin{array}{l}5.460 \\
0.223\end{array}$ & $\begin{array}{r}1.365 \\
-0.067\end{array}$ \\
\hline$c_{2}(0)=8$ & $\begin{array}{r}3.891 \\
-0.276\end{array}$ & $\begin{array}{r}3.891 \\
-0.276\end{array}$ & $\begin{array}{r}7.475 \\
-0.491\end{array}$ & $\begin{array}{r}0.031 \\
-0.002\end{array}$ & $\begin{array}{r}7.301 \\
-0.199\end{array}$ & $\begin{array}{l}0.000 \\
0.000\end{array}$ & $\begin{array}{l}7.024 \\
0.024\end{array}$ & $\begin{array}{l}0.000 \\
0.000\end{array}$ & $\begin{array}{l}6.725 \\
0.225\end{array}$ & $\begin{array}{l}0.000 \\
0.000\end{array}$ \\
\hline
\end{tabular}

Notes: Parameter values for this example are $\bar{c}=1, \delta=0.9$, and $V=10 . c_{1}\left(x_{1}\right)$ and $c_{2}\left(x_{2}\right)$ show intrinsic costs for supplier 1 and 2, respectively. $\pi$ s indicate the current period expected profits for suppliers.

procurement, $\bar{\lambda}_{1}$ are recorded in the cells corresponding to each state.

The example illustrates how the leader is more likely to be selected in each state. For instance, beginning in state $(0,0)$ producer 1 is selected with probability 0.5 . If he wins the procurement, then he is selected with probability 0.996 to win the next procurement in state $(1,0)$. Each time the leader is selected he gains additional experience, and he becomes more likely to be selected in the next period. (This is reflected in the increasing transition probabilities moving left to right along each row.) As a result, the leader's expected payoff increases as he gains experience, while producer 2's expected payoff declines.

Notice eventually the leader may acquire such a cost advantage that producer 2 is precluded from future procurements. ${ }^{20}$ This occurs in states $(2,0),(3,0)$, and $(4,0)$ where producer 1 is selected with certainty. Tipping is more likely to occur when more experience can be gained from production. Table 2 reveals for instance that tipping does not arise if the sup-

\footnotetext{
${ }^{20}$ Tipping occurs quite frequently in high-tech markets, where learning economies bestow an advantage to one supplier, who is able to dominate the market. Tipping also arises in communication and computer component markets where network externalities make it attractive for consumers to purchase from the same supplier.
}

pliers begin in state $(1,1)$ rather than $(0,0)$ where learning is exhausted after only three production experiences. In addition, tipping is less likely to occur when the economies from learning are not as pronounced or as the degree of transient cost variation is large. In those instances, the procurer prefers purchasing from both contractors to maintain competition.

When tipping arises, the buyer can purchase supplies at reduced prices initially, as suppliers offer discounts to gain experience and achieve a lead over their rival. ${ }^{21}$ In effect the eventual benefits from learning by doing are brought forward in time for the procurer to enjoy initially. These initial discounts compensate for the higher prices the buyer will face once she is locked in to a single supplier. This temporal pattern of pricing is reflected in Table 3 , which records the expected payments contractors receive and their single-period profits for each state in the competition. Notice single-period profits are negative for each seller during the initial stages of the procurement.

\footnotetext{
${ }^{21}$ This type of pricing is similar to penetration pricing observed in communication and computer component markets. Suppliers heavily discount initial prices to achieve a large installed base of customers. Suppliers may earn negative net revenues initially as they invest in building an installed base. However, once the customers are locked in, suppliers can raise prices and generate significant profits as a payback for their initial investment.
} 
TABle 4-Total SuRPlus and Buyer's Surplus

\begin{tabular}{|c|c|c|c|c|c|c|c|}
\hline \multirow[b]{2}{*}{ Cost } & \multicolumn{2}{|c|}{$c_{1}(0)=8$} & $c_{1}(1)=7.5$ & $c_{1}(2)=7$ & $c_{1}(3)=6.5$ & \multicolumn{2}{|c|}{$c_{1}(4)=6$} \\
\hline & $W(\mathbf{x})$ & $B(\mathbf{x})$ & $W(\mathbf{x}) \quad B(\mathbf{x})$ & $W(\mathbf{x}) \quad B(\mathbf{x})$ & $W(\mathbf{x}) \quad B(\mathbf{x})$ & $W(\mathbf{x})$ & $B(\mathbf{x})$ \\
\hline$c_{2}(4)=6$ & 35.000 & 32.753 & 34.65232 .334 & 35.45232 .681 & 36.21833 .091 & 36.667 & 33.333 \\
\hline$c_{2}(3)=6.5$ & 34.500 & 32.454 & 34.15932 .056 & 34.98132 .423 & 35.76332 .843 & 36.218 & 33.091 \\
\hline$c_{2}(2)=7$ & 33.550 & 31.908 & 33.24131 .556 & 34.14931 .976 & 34.98132 .423 & 35.452 & 32.681 \\
\hline$c_{2}(1)=7.5$ & 32.191 & 31.208 & 32.08431 .002 & 33.24131 .556 & 34.15932 .056 & 34.652 & 32.334 \\
\hline$c_{2}(0)=8$ & 30.639 & 30.305 & 32.19131 .208 & 33.55031 .908 & 34.50032 .454 & 35.000 & 32.753 \\
\hline
\end{tabular}

Notes: Parameter values for this example are $\bar{c}=1, \delta=0.9$, and $V=10 . c_{1}\left(x_{1}\right)$ and $c_{2}\left(x_{2}\right)$ show intrinsic costs for supplier 1 and 2, respectively.

\section{The Value of Experience and the Rate of Learning}

In a competitive procurement where suppliers learn from experience, does the buyer always benefit from the learning process? Does total surplus increase with learning? Under competition, is the rate at which suppliers learn socially optimal? A useful first-best benchmark for examining these questions is the completeinformation case in which the buyer is perfectly informed of each supplier's current cost. In the complete-information case, social surplus from procurement is maximized, and this first-best procurement equilibrium is characterized in the following: ${ }^{22}$

PROPOSITION 5: A unique and seller-symmetric equilibrium exists for the first-best case in which:
(a) $\lambda_{1}^{*}\left(k, l, c^{\prime}, c^{\prime \prime}\right)=\lambda_{1}^{*}\left(k, l, c^{\prime \prime}, c^{\prime}\right)$
(b)

$$
S_{i}^{*}(\mathbf{x})=0
$$
(c) $B *(\mathbf{x})=W^{*}(\mathbf{x})$

$$
=E_{c}\left\{\max _{i \in\{1,2\}} z_{i}^{*}\left(\mathbf{x}, c_{i}\right)\right\}+\delta W^{*}(\mathbf{x})
$$
(d) $z_{i}^{*}\left(\mathbf{x}, c_{i}\right)=V-c\left(x_{i}\right)-c_{i}+\delta \Delta_{x_{i}} W^{*}(\mathbf{x})$
(e) $\quad \Delta_{x_{i}} B *(\mathbf{x}) \geq 0$.

\footnotetext{
${ }^{22}$ The "*”" superscript corresponds to the first-best equilibrium values.
}

A comparison of Propositions 1 and 5 shows that the first-best equilibrium, while qualitatively similar to the procurement equilibrium, does differ in a few important respects. Condition (c) of Proposition 5 indicates that in the first-best equilibrium the procurer can tax away all producer rent when she knows costs. In contrast to the private-information case, the buyer can make supply decisions that maximize total surplus, without regard for how future competition between suppliers will be affected. One implication of this is that the procurer's surplus increases as either supplier gains experience. Experience reduces the supplier's cost and the procurer benefits from having access to a lower-cost supplier. Surprisingly, we find this is not necessarily true in the case where suppliers' costs are private information in the procurement setting.

PROPOSITION 6: When supplier costs are private information, the procurer's surplus and total surplus may decline when the lagging supplier becomes more experienced.

We illustrate these findings by the example summarized in Table 4. Notice the procurer's surplus, $B$, and total surplus, $W$, decline as the experience state moves from $(1,0)$ to $(1,1)$ and supplier 2 gains experience. In instances where the supplier's costs are unknown to the procurer, he relies upon competition between suppliers to reduce acquisition costs. Apparently when the leading supplier is slightly ahead, the producers compete more vigorously for the next-period sale, than if they have the same 
level of experience and expected costs. As a result the procurer may be harmed as the follower acquires more experience. The example also illustrates the possibility of a decline in total surplus, $W$, as the lagging producer acquires more experience.

With competitive procurement the buyer determines the rate suppliers learn by her assignment of production each period. Learning is maximized when production is assigned to the experienced supplier enabling the leader to move down his learning curve most rapidly. The procurer may forgo some learning to maintain cost parity among the suppliers and also to exploit a temporary cost advantage of the lagging supplier. This brings into question whether suppliers learn at an efficient rate under competitive procurement. To consider this we compare the learning rates under competition and under the first-best procurement case for a twostage learning process. $^{23}$

PROPOSITION 7: For $\delta \in(0,1)$ and $h=2$,

$$
\bar{\lambda}_{1}^{*}(\mathbf{x}) \geq \bar{\lambda}_{1}(\mathbf{x}) ;\left(\text { with }>\text { when } h \geq x_{1}>x_{2}\right) \text {. }
$$

When the buyer is perfectly informed of each supplier's costs he can allow more rapid learning without harm to future competition. When the procurer is imperfectly informed of production costs, he relies on competition among suppliers to regulate his acquisition costs. Consequently, the procurer's preference for balanced competition pushes learning below the efficient level.

\section{Policies for Affecting the Rate of Learning}

\section{A. Information Sharing and Merging of Suppliers}

The procurer can affect the rate suppliers learn by its acquisitions policy. One such policy the DoD has adopted requires current contractors to provide detailed production plans which other contractors may use in future procurements. In effect the government owns the intel-

\footnotetext{
${ }^{23}$ We conjecture this result holds generally for any number of learning stages.
}

lectual property developed by its suppliers and it may share this knowledge with any other prospective supplier. ${ }^{24}$ The intended effect of this is to maintain parity among competing contractors by giving them access to the same knowledge and technology. ${ }^{25}$

It is unclear whether this policy would enable procurers to reduce their costs of acquisition. On the one hand, requiring suppliers to share information reduces the benefits of their acquiring experience. Consequently suppliers bid less aggressively as acquiring experience is less beneficial and the procurer's acquisition cost increases. On the other hand, knowledge is diffused more rapidly when suppliers share information. This enables all suppliers to reduce their cost more rapidly than if information were proprietary.

To analyze the net impact of these different effects, we suppose the procurement process begins in state $\left(x_{1}^{0}, x_{2}^{0}\right)$ where suppliers 1 and 2 initially have knowledge levels, $x_{i}^{0}$ for supplier $i$ which may differ. For instance, if supplier 1 was primarily responsible for developing a prototype for the buyer, he may have acquired more knowledge and production experience initially than supplier 2 . We compare the procurement equilibrium for the setting where knowledge is shared among suppliers in all periods, with the case where knowledge is always proprietary. In both settings procurement begins at the same initial state, $\left(x_{1}^{0}, x_{2}^{0}\right)$, and each contractor's transitory cost of supply continues to be private knowledge. Our findings are summarized in:

PROPOSITION 8: The buyer prefers information sharing whenever the initial information gap, $x_{1}^{0}-x_{2}^{0}$, is sufficiently large. Otherwise the procurer prefers not to exchange infor-

\footnotetext{
${ }^{24}$ Government contractors are obliged to supply their project sponsor with design plans and production specifications whenever the project is totally government funded or when the sponsor has Government Purpose License Rights to the project. See the Report of the Defense Science Board Task Force on Antitrust Aspects of Defense Industry Consolidation (Defense Science Board, 1994 p. 23).

${ }^{25}$ In practice the sharing of information may be incomplete, as complete transfer of one supplier's experience and knowledge to another may not arise. We abstract from this possibility in the analysis to follow.
} 
mation. Sellers' preferences for information sharing are directly opposite to those of the buyer. Total surplus increases under information sharing.

In cases where the leading producer begins with a significant advantage over his rival, the buyer will prefer information sharing. The aggregate seller surplus will decline. Although this required sharing of information reduces the incentives for an individual contractor to gain experience, this is more than offset by the more rapid diffusion of knowledge which results. However, when suppliers are closely matched initially, the buyer benefits more from the increased competition between producers than from the diffusion of information. The buyer optimally commits to prohibit information from being shared or diffused. ${ }^{26}$ Suppliers, on the other hand, prefer sharing of information since it reduces competition between them.

In some instances, the buyer can not control technologies developed by its suppliers. For these instances, allowing the merger of suppliers is another avenue for affecting the rate of learning. The collective design and manufacturing experience of rival producers can be consolidated when rival firms merge. ${ }^{27}$ The buyer, however, prefers information sharing to the merging of producers, since all competition is lost once rivals merge. Proposition 8 therefore suggests that mergers will only be supported by the procurer in instances where information sharing is not feasible and when the knowledge gap between the suppliers is so large as to preclude any effective future competition between the suppliers. ${ }^{28}$

\footnotetext{
${ }^{26}$ The buyer must be able to prevent information sharing ex ante, as she will always prefer to share information ex post after one of the suppliers has acquired more information.

${ }^{27}$ See Jeffrey A. Drezner et al. (1992) for a discussion of how mergers preserve and consolidate design expertise among rival contractors.

${ }^{28}$ These circumstances come close to approaching the conditions required for a "failing firm defense" for acquisition, under which a firm is permitted to acquire a rival when the rival and its productive assets would otherwise exit from the market. Despite the drastic change in market structure engendered by acquisitions, the U.S. defense industry has been permitted to consolidate from 21 sup-
}

\section{B. Rotating Procurement Managers}

In practice, procurement managers of major weapon systems rotate frequently between assignments. The average tenure of a procurement manager is two years. This compares with an average duration of 10 to 20 years for most major acquisition programs. The frequent rotation of procurement managers has been cited as a major source of inefficiency in defense procurement. ${ }^{29}$ This arises because managers are incented to control the costs of acquisition during their tenure to build a reputation for good project management. The manager cares only to minimize current acquisition costs, with no regard for how their decisions impact on future procurement costs.

Given these incentives to maximize current performance, how does the rotation of managers affect the rate of learning in procurement? To examine this question, we assume the current buyer lasts for a single period. Her effective discount factor, $\delta_{B}$, equals zero. The current buyer is replaced by another who conducts the next-period procurement, and so on. The suppliers, however, are long-lived and have a discount factor $\delta \in(0,1)$. All agents are perfectly informed about the state, $\mathbf{x}$, when they take an action. The MPE for this model is derived exactly as before except that the buyer's discount factor $\delta_{B}$ becomes zero.

For this case we find a unique, symmetric seller MPE exists with these properties. In the following proposition, the superscript " 0 " refers to the short-lived buyer case, and $B^{0}(\mathbf{x})$ represents the present-value sum of all buyers' surpluses from the current period onward, given the current state, $\mathbf{x} .^{30}$

pliers in 1993 to just five currently operating suppliers who include: Boeing, Litton Industries, Lockheed-Martin, Northrop-Grumman, and Raytheon.

${ }^{29}$ Most industry analysts including Fox (1988) and Gansler (1989) and several review commissions including the heralded Packer Commission conclude that the frequent rotation of managers contributes significantly to inefficiency in defense acquisitions.

${ }^{30}$ Our model with a sequence of short-term buyers is simlar to Cabral and Riordan (1994). However, Cabral and Riordan assume that sellers (rather than buyers) make offers, and more importantly that buyers are the ones with private information rather than the suppliers. Given these 
PROPOSITION 9: Suppose buyers are short lived with $\delta_{B}=0$. A unique and seller-symmetric $M P E$ exists satisfying:

$$
\begin{aligned}
S_{i}^{0}(\mathbf{x})= & E_{c}\left\{\lambda_{i}^{0}(\mathbf{x}, \mathbf{c}) \frac{F\left(c_{i}\right)}{f\left(c_{i}\right)}\right\} \\
& +\delta S_{i}^{0}\left(x_{i}, x_{j}+1\right) ;
\end{aligned}
$$

and

(b) $B^{0}(\mathbf{x})$

$$
=\frac{E_{c}\left\{\max _{i \in\{1,2\}} z_{i}^{0}\left(\mathbf{x}, c_{i}\right)\right\}-\delta\left(\Delta_{x_{2}} S_{1}^{0}(\mathbf{x})+\Delta_{x_{1}} S_{2}^{0}(\mathbf{x})\right)}{1-\delta}
$$

where $z_{i}^{0}\left(\mathbf{x}, c_{i}\right) \equiv V-c\left(x_{i}\right)-c_{i}-F\left(c_{i}\right) / f\left(c_{i}\right)$ $+\delta \Delta_{x_{i}}\left(S_{i}^{0}(\mathbf{x})+S_{j}^{0}(\mathbf{x})\right)$.

The rivalry between suppliers is qualitatively the same whether they face long- or short-term buyers. In both cases, suppliers want to win the next procurement to compete more effectively in the future. The supplier benefitting the most from winning a current contract will underbid his rival. The short-term buyer benefits from this bidding competition. By awarding production to supplier $i$, for instance, she captures the additional future supplier surplus $\delta \Delta_{x_{i}}\left(S_{i}^{0}(\mathbf{x})+\right.$ $\left.S_{j}^{0}(\mathbf{x})\right)$ that is generated. This means a shortlived buyer will tend to favor the supplier benefitting the most from winning the current competition. ${ }^{31}$ In contrast, a long-lived buyer will want to maintain parity among rival suppliers. The implication of this is summarized in the following:

PROPOSITION 10: For $\delta$ sufficiently large, learning occurs more rapidly with a sequence of short-lived buyers than with a long-lived buyer. Also $\bar{\lambda}_{1}^{0}(\mathbf{x})>\bar{\lambda}_{1}(\mathbf{x})$ whenever $h \geq x_{1}>x_{2}$.

According to Proposition 10, the short-lived manager is more likely to select the leading

\footnotetext{
differences, it is not possible to compare our findings directly with those of Cabral and Riordan.

${ }^{31}$ The suppliers' current production costs will also determine who wins the procurement. But all else being equal, the supplier benefitting the most from winning the current competition will prevail.
}

contractor to be her supplier. By selecting the more-experienced supplier, the manager reduces the cost of completing the next procurement. Although this may decrease future competition to the detriment of future procurement managers, the current manager is concerned only with short-run performance. As a result of this strategy the leading supplier is chosen more frequently, leading to a greater chance of market dominance and tipping. ${ }^{32}$

\section{Conclusion}

Learning through production is an important phenomenon in high-technology markets, including software development, data processing, communications, aeronautics, and defense. Procurers can reduce their current and future acquisition costs by strategically managing learning among rival suppliers. This paper characterizes this management process by examining the market equilibrium that arise from repeated competition between rival suppliers. Two main conclusions emerge from our analysis. First, managing dynamic competition requires the procurer to balance the advantages of learning by doing against a future reduction in market competition occurring when one supplier becomes dominant. When learning economies are pronounced the buyer eventually purchases exclusively from the more experienced supplier. When learning economies are small, the buyer maintains competition among rival suppliers by rotating his purchases.

Second, the rate of learning in competitive procurement settings is too slow. Further, the buyer may sometimes be harmed if the lagging supplier learns at the expense of the more experienced producer. To facilitate more rapid learning, it may be beneficial for the buyer to require the suppliers to share information. This occurs when the experience levels of the suppliers varies significantly. Another strategy to promote more rapid learning is to reduce the tenure of procurement managers. Short-lived

\footnotetext{
${ }^{32}$ The possibility exists that the buyers' long-run expected surplus from procurement is higher when program managers have limited tenure than when they have long tenure, though we have not been able to establish general conditions for this to arise.
} 
buyers favor more-experienced suppliers which expedites learning.

The model we have employed to analyze dynamic competition is special in several respects. One potentially interesting extension of our analysis is to consider the interaction of several competing firms. The dynamics of firm rivalry as well as the desirability of permitting firms to share information may depend on the number of suppliers in the market. Further, it may be interesting to investigate how different learning processes, which permit knowledge to be forgotten when firms are inactive, affect the dynamics of market competition. In some instances the buyer may be the party who learns from experience how to better utilize the products he procures from specific producers. Our analysis could fruitfully be extended to these settings as well.

The results of our paper point to the need to develop a theory of competition policy that applies to dynamic markets where learning and innovation change the capacity of firms to compete against each other over time. In markets where learning is important, or where there are other types of demand-side and supply-side externalities, it is likely that eventually a single firm becomes the dominant supplier of a given product line. Competition among producers takes place early in the product cycle. The emergence of a single dominant producer is not necessarily undesirable from a competition viewpoint; it simply means that one must consider the entire product life cycle realizing the monopoly position won by the dominant firm is a payoff for the investment the firm makes initially to obtain market dominance. In such markets the sharing of information between rivals or even the possible acquisition of a failing firm by a dominant supplier may enhance efficiency. The real form of competition in dynamic settings is between firms learning and innovating, not the static-style competition we are more accustomed to.

\section{ApPendix: ProOfs of LemMa 1 AND PROPOSITION 1}

\section{PROOF OF LEMMA 1:}

Implementation of an allocation $\left\{P_{i}(\mathbf{x}, \mathbf{c})\right.$, $\left.\lambda_{i}(\mathbf{x}, \mathbf{c})\right\}$ for $i=1,2$ requires incentive compatibility (IC) and individual rationality
(IR) to be satisfied. Since $S_{i}\left(\mathbf{x}, \mathbf{c}_{i}\right)$ is weakly decreasing in $c_{i}$ by (IC), it suffices to set $S_{i}(\mathbf{x}, \bar{c})=\delta S_{i}\left(x_{i}, x_{j}+1\right)$ to satisfy (IR). Together with the second part of (IC), this implies

$$
\begin{aligned}
\text { (A1) } & S_{i}\left(\mathbf{x}, c_{i}\right) \\
= & S_{i}(\mathbf{x}, \bar{c})-\int_{c_{i}}^{\bar{c}}-\lambda_{i}\left(\mathbf{x}, c_{i}^{\prime}\right) d c_{i}^{\prime} \\
= & \delta S_{i}\left(x_{i}, x_{j}+1\right)+\int_{c_{i}}^{\bar{c}} \lambda_{i}\left(\mathbf{x}, c_{i}^{\prime}\right) d c_{i}^{\prime} .
\end{aligned}
$$

Substituting (A1) into (3) in the text and solving for $P_{i}\left(\mathbf{x}, c_{i}\right)$ yields the expression for $P_{i}\left(\mathbf{x}, c_{i}\right)$ in Lemma 1.

\section{PROOF OF PROPOSITION 1:}

The claims of the proposition are established inductively by first showing the posited properties hold for boundary states, and then that they are also true for interior states. Since most of the proofs are straightforward, we have omitted them. The complete proofs of all propositions are available from the authors.

To establish a unique MPE exists, we argue by induction starting at state $(h, h)$. Note that all states $(h+l, h+m)$ are payoff-equivalent to state $(h, h)$ for $l, m \geq 0$ by Assumption 1 .

Consequently, if a unique MPE exists for state $(h, h)$, the same unique equilibrium exists for all states $(h+l, h+m)$.

State $(h, h):$ At state $(h, h)$, we have $\Delta_{x_{i}} B(\mathbf{x})=$ $\Delta_{x_{i}} W(\mathbf{x})=\Delta_{x_{i}} S_{j}(\mathbf{x})=0$, since the MPE does not vary as either $x_{1}$ or $x_{2}$ increases. Consequently, (5) implies $\lambda_{i}(\mathbf{x}, \mathbf{c})$ is uniquely defined by

$$
\lambda_{i}(\mathbf{x}, \mathbf{c})= \begin{cases}1 & \text { if } z_{i}\left(\mathbf{x}, c_{i}\right) \geq z_{j}\left(\mathbf{x}, c_{j}\right) \\ 0 & \text { otherwise. }\end{cases}
$$

Substituting for $z_{i}$ and $z_{j}$ and recalling that $c_{i}$ is uniformly distributed on $[0, \bar{c}]$, equations (A2) and (5) imply: 


$$
B(h, h)=\frac{V-c(h)-\frac{2 \bar{c}}{3}}{1-\delta}
$$

and equations (2), (3), and Lemma 1 imply

$$
S_{i}(h, h)=\frac{\frac{\bar{c}}{6}}{1-\delta} .
$$

Boundary States ( $h, h-l), l \geq 1$ : A boundary state exists whenever $x_{i} \geq h$ for $i=1,2$. Assume a unique MPE exists for all states $(h, h+1-l), l \geq 1$, so that $B(h, h+1-l)$, $S_{i}(h, h+1-l)$, and $W(h, h+1-l)$ exist and are well defined.

Equation (A2) implies that seller 1 is selected to operate in state $\mathbf{x}$ whenever $z_{1}\left(\mathbf{x}, c_{1}\right) \geq z_{2}$ $\left(\mathbf{x}, c_{2}\right)$. This implies

$$
\lambda_{1}(\mathbf{x}, \mathbf{c})= \begin{cases}1 & \text { if } c_{1} \leq c_{2}+\frac{a(\mathbf{x})}{2} \\ 0 & \text { otherwise }\end{cases}
$$

where

$$
\begin{aligned}
a(\mathbf{x})= & c\left(x_{2}\right)-c\left(x_{1}\right) \\
& +\delta\left[\Delta_{x_{1}} W(\mathbf{x})-\Delta_{x_{2}} W(\mathbf{x})\right] .
\end{aligned}
$$

Define $\bar{\lambda}_{1}(a)$ to be the expected probability that seller 1 operates given $a$. Assume for now that $a \geq 0$. We verify below this is indeed the case. For $a \geq 0$ and $c_{1}$ uniformly distributed, $\bar{\lambda}_{1}(a)$ is given by

$$
\text { (A5) } \begin{aligned}
& \bar{\lambda}_{1}(a) \\
& = \begin{cases}\int_{c_{1} \leq c_{2}+a / 2} \int_{c_{2}}\left(\frac{1}{\bar{c}}\right)^{2} d c_{2} d c_{1} \\
=1-\frac{(2 \bar{c}-a)^{2}}{8 \bar{c}^{2}} & \text { for } a \in[0,2 \bar{c}] \\
1 & \text { for } a>2 \bar{c}\end{cases}
\end{aligned}
$$

and

$$
\bar{\lambda}_{2}(a)=1-\bar{\lambda}_{1}(a) .
$$

The expected cost of supply in state $\mathbf{x}$ with $a(\mathbf{x})$ is $c\left(x_{1}\right)+\lambda_{2}(a(\mathbf{x}))\left[c\left(x_{2}\right)-c\left(x_{1}\right)\right]+$ $d(a(\mathbf{x}))$, where

$$
\begin{aligned}
& \text { (A7) } d(a) \\
& =\int_{c_{1}} \int_{c_{2}}\left[\lambda_{1}(\mathbf{x}, \mathbf{c}) c_{1}+\lambda_{2}(\mathbf{x}, \mathbf{c}) c_{2}\right] \frac{d c_{1} d c_{2}}{\bar{c}^{2}} \\
& =\bar{c}\left(\frac{\left.8-\left(\frac{a}{\bar{c}}\right)^{3}+3\left(\frac{a}{\bar{c}}\right)^{2}\right)}{24}\right) \text { for } a \in[0,2 \bar{c}] \\
& \begin{array}{ll}
\text { (A8) } \quad d(a)=\frac{\bar{c}}{2} & \text { for } a>2 \bar{c} .
\end{array}
\end{aligned}
$$

Employing (A4)-(A8), we can represent $W(h, h-l)$ as

$$
\begin{aligned}
& W(h, h-l) \\
& =V-c(h)-\lambda_{2}(a(h, h-l)) a(h, h-l) \\
& \quad-d(a(h, h-l))+\delta W(h, h-l)
\end{aligned}
$$

or

$$
\text { (A9) } \begin{aligned}
& W(h, h-l) \\
= & \frac{V-c(h)-\lambda_{2}(a(h, h-l)) a(h, h-l)}{1-\delta} \\
& -\frac{d(a(h, h-l)}{1-\delta} .
\end{aligned}
$$

Equation (A4) implies in a boundary state, $(h$, $h-l)$ that $a(h, h-l)$ is given by

$$
\begin{aligned}
\text { (A10) } & a(h, h-l) \\
= & c(h-l)-c(h)+\delta[W(h, h-l) \\
& -W(h, h+1-l)] \\
= & \frac{\delta}{1-\delta} V-c(h)-\lambda_{2}(a(h, h-l)) \\
& \times a(h, h-l)-d(a(h, h-l)) \\
& +c(h-l)-c(h)-W(h, h+1-l) .
\end{aligned}
$$


where the equality of (A10) follows from substituting for $W(h, h-l)$ from (A9) into (A10). Rearranging (A10) and substituting for $\bar{\lambda}_{2}(a)$ from (A6) and for $d(a)$ from (A7), we obtain the following cubic equation in $a$

$$
\begin{gathered}
(1-\delta) a+\delta a \frac{(2 \bar{c}-a)^{2}}{8 \bar{c}^{2}} \\
+\bar{c}\left(\frac{8-\left(\frac{a}{\bar{c}}\right)^{3}+3\left(\frac{a}{\bar{c}}\right)^{2}}{24}\right) \\
+(1-\delta)[c(h)-c(h-l)] \\
+\delta[1-\delta W(h, h+1-l) \\
-(V-c(h))]=0 .
\end{gathered}
$$

One can show that either (i) there is a unique real root $a \in(0,2 \bar{c}]$ solving (A11), or (ii) there is no real root $a \in(0,2 \bar{c}]$ satisfying (A11). When (i) occurs, the real root is $a=a(h$, $h-l)$ which uniquely defines $W(h, h-l)$, $B(h, h-l)$, and $S_{i}(h, h-l)$ for $i=1,2$. Otherwise for case (ii), a corner solution occurs with $a(h, h-l)=2 \bar{c}, \bar{\lambda}_{1}(a(h, h-l))=1$, and seller 1 is always selected to produce.

It is straightforward to verify there does not exist an $a<0$ satisfying (A10). With this, our induction argument for the boundary states is complete. We have demonstrated a unique MPE exists for state $(h, h-l)$ whenever a unique MPE exists for states $(h, h+1-l), l \geq 1$. Notice the same argument holds for states $(h+$ $1-l, h)$ due to the symmetry of our model.

Interior States $(m, l), h>m \geq l$ : Arguing by induction, assume a unique and seller-symmetric MPE exists for all states $(m+i, l+j)$ for $i, j \geq 0$ (with at least one strict inequality). Recall $a(m, l)$ is defined by equation (A4) as

$$
\begin{aligned}
& \text { (A12) } \quad a(m, l) \\
& =c(l)-c(m)+\delta[W(m+1, l) \\
& \quad-W(m, l)-(W(m, l+1)-W(m, l))] \\
& =c(l)-c(m)+\delta[W(m+1, l) \\
& \quad-W(m, l+1)] .
\end{aligned}
$$

Since $W(m+1, l)$ and $W(m, l+1)$ exist and are well defined, $a(m, l)$ is uniquely determined by (A12). The value functions $W(m, l)$, $S_{i}(m, l)$, and $B(m, l)$ are uniquely determined as a function of $a(m, l)$. This enables us to determine $W(m, l)$ according to the equation,

$$
\begin{aligned}
& W(m, l) \\
= & V-c(m)+\delta W(m+1, l) \\
- & \lambda_{2}(a(m, l)) a(m, l)-d(a(m, l))
\end{aligned}
$$

where $\bar{\lambda}_{2}(a)$ is given by (A5) and (A6). The value functions $B(m, l)$ and $S_{i}(m, l)$ can be determined uniquely from (A12) and (A13).

This completes the induction argument for interior states. Note the argument is the same for states $(l, m)$ due to the symmetry of our model.

\section{REFERENCES}

Alchian, Armen. "Reliability of Progress Curve in Airframe Production." Econometrica, October 1963, 31(4), pp. 679-93.

Anton, James J. and Yao, Dennis A. "Second Sourcing and the Experience Curve: Price Competition in Defense Procurement." RAND Journal of Economics, Spring 1987, 18(1), pp. 57-76.

Bergemann, Dirk and Valimaki, Juuso. "Learning and Strategic Pricing." Econometrica, September 1996, 64(5), pp. 1125-50.

Burguet, Roberto. "Optimal Repeated Purchases When Sellers Are Learning about Costs." Journal of Economic Theory, February 1996, 68(2), pp. 440-55.

Cabral, Luis M. B. and Riordan, Michael H. "The Learning Curve, Market Dominance, and Predatory Pricing." Econometrica, September 1994, 62(5), pp. 1115-40.

Dana, James D. and Spier, Kathryn E. "Designing a Private Industry: Government Auctions with Endogenous Market Structure." Journal of Public Economics, January 1994, 53(1), pp. 127-47.

Defense Science Board. Report of the defense science board task force on antitrust aspects of defense industry consolidation. 
Washington, DC: U. S. Department of Defense, April 1994.

Demski, Joel S.; Sappington, David E. M. and Spiller, Pablo T. "Managing Supplier Switching." RAND Journal of Economics, Spring 1987, 18(1), pp. 77-97.

Drezner, Jeffrey A.; Smith, Giles K.; Horgan, Lucille E.; Rogers, Curt and Schmidt, Rachel. Maintaining future military aircraft design capability. Santa Monica, CA: RAND Corporation (RAND/R-4199-AF), 1992.

Fox, John R. The defense management challenge: Weapons acquisitions. Cambridge, MA: Harvard University Press, 1988.

Fudenberg, Drew and Tirole, Jean. Game theory. Cambridge, MA: MIT Press, 1991.

Gansler, Jacques S. Affording defense. Cambridge, MA: MIT Press, 1989.

Gruber, Harald. "Learning by Doing and Spillovers: Further Evidence for the Semiconductor Industry." Review of Industrial Organization, December 1998, 13(6), pp. 697-711.

Hirsch, Werner Z. "Manufacturing Progress Functions." Review of Economics and Statistics, May 1952, 34(2), pp. 143-55. . "Firm Progress Ratios." Econometrica, April 1956, 24(2), pp. 136-43.

Jehiel, Philippe; Moldovanu, Benny and Stacchetti, Ennio. "How (Not) to Sell Nuclear Weapons." American Economic Review, September 1996, 86(4), pp. 814-29.

. "Multidimensional Mechanism Design for Actions with Externalities." Journal of Economic Theory, April 1999, 85(2), pp. 258-93.

Joskow, Paul L. and Rozanski, George A. "The Effects of Learning by Doing on Nuclear Power Plant Operating Reliability." Review of Economics and Statistics, May 1979, 61(2), pp. 161-68.

Keller, Godfrey and Rady, Sven. "Optimal Experimentation in a Changing Environment." Review of Economic Studies, July 1999, 66(3), pp. 475-507.

Laffont, Jean J. and Tirole, Jean. "Auctioning Incentive Contracts." Journal of Political Economy, October 1987, 95(5), pp. 921-37.

. "Repeated Actions of Incentive Contracts, Investment, and Bidding Parity with an Application to Takeovers." RAND Journal of Economics, Winter 1988, 19(4), pp. 51637.

- A theory of incentives in procurement and regulation. Cambridge, MA: MIT Press, 1993.

Lester, Richard K. and McCabe, Mark J. "The Effect of Industrial Structure on Learning by Doing in Nuclear Power Plant Operation." RAND Journal of Economics, Autumn 1993, 24(3), pp. 418-38.

Lewis, Tracy R. "Preemption, Divestiture, and Forward Contracting in a Market Dominated by a Single Firm." American Economic Review, December 1983, 73(5), pp. 1092-1101.

Lieberman, Marvin B. "The Learning Curve and Pricing in the Chemical Processing Industries." RAND Journal of Economics, Summer 1984, 15(2), pp. 213-28.

McAfee, Preston R. and McMillan John. "Competition for Agency Contracts." RAND Journal of Economics, Summer 1987, 18(2), pp. 296-307.

Nye, William W. "Firm-Specific Learning by Doing in Semiconductor Production: Some Evidence from the 1986 Trade Agreement." Review of Industrial Organization, June 1996, 11(3), pp. 383-94.

Preston, Lee E. and Keachie, E. C. "Cost Functions and Progress Functions: An Integration." American Economic Review, March 1964, 54(2), pp. 100-07.

Rapping, Leonard. "Learning and World War II Production Functions." Review of Economics and Statistics, February 1965, 47(1), pp. 8186.

Riordan, Michael H. and Sappington, David E. M. "Awarding Monopoly Franchises." American Economic Review, June 1987, 77(3), pp. 375-87.

Roberts, Peter C. and Burwell, Calvin C. The learning function in nuclear reactor operation and its implications for siting policy. Oak Ridge, TN: Institute for Energy Analysis, 1981 .

Rustichini, Aldo and Wolinsky, Asher. "Learning about Variable Demand in the Long Run." Journal of Economic Dynamics and Control, 1995, 19(5-7), pp. 1283-92.

Spence, Michael A. "The Learning Curve and Competition." Bell Journal of Economics, Spring 1981, 12(1), pp. 49-70. 
Stobaugh, Robert B. and Townsend, Patrick L. "Price Forecasting and Strategic Planning: The Case of Petrochemicals." Journal of Marketing Research, 1975, 12, pp. 19-29.

Sultan, Ralph G. M. "Pricing in Electrical Oligopoly." Mimeo, Harvard University, 1975.

Thompson, Peter. "How Much Did the Liberty Shipbuilders Learn? New Evidence for an Old Case Study." Journal of Political Econ- omy, February 2001, 109(1), pp. 103-37.

Thornton, Rebecca A. and Thompson, Peter. "Learning from Experience and Learning from Others: An Exploration of Learning and Spillovers in Wartime Shipbuilding." American Economic Review, December 2001, 91(5), pp. 1350-68.

Wright, T. P. "Factors Affecting the Cost of Airplanes." Journal of Aeronautical Sciences, 1936, 3, pp. 122-28. 